\title{
PERILAKU IBU RUMAH TANGGA DALAM PEMBERANTASAN SARANG NYAMUK DI KAWASAN PESISIR WAIHERU AMBON
}

\author{
Rahwan Ahmad ${ }^{1}$, Prasetyawati ${ }^{2}$ \\ Jurusan Sanitasi, Poltekkes Kemenkes Maluku \\ rahwan.ahmad@gmail.com ${ }^{1}$, prasetyawati85@gmail.com²
}

\begin{abstract}
Education and behavior (knowledge, attitudes and actions) about healthy living are important things, especially applied in life, so as not to fall sick so that they can carry out activities properly. Worldwide, there are more than 2500 species of mosquitoes, although most of these mosquito species are not associated with disease. Larva eradication practice can be done with $3 \mathrm{M}$ plus. The role of the community in eradicating mosquito nests is prioritized by housewives because they are generally responsible for taking care of the household including household hygiene problems. Study was to determine the relationship between education and knowledge with the behavior of housewives in eradicating mosquito nests. Use cross-sectional analytic, the sampling technique used simple random sampling and inclusion criteria in order to obtain 50 respondents. Data analysis used Chi-Square with a significant level of $95 \%$ with a significance value of 5\%. Respondents with higher education and good behavior were $73.1 \%$. Respondents with low education and bad behavior were $70.8 \%$. Respondents with good knowledge and good behavior were 75\%, respondents with bad knowledge and bad behavior were $77.3 \%$. There is a relationship between education and the behavior of housewives in eradicating mosquito nests, and there is a relationship between knowledge and behavior of housewives in eradicating mosquito nests.
\end{abstract}

Keyword: Behavior, Education, Household,Knowledge,

\begin{abstract}
ABSTRAK
Pendidikan dan perilaku (pengetahuan, sikap dan tindakan) tentang hidup sehat adalah hal yang penting terutama diterapkan dalam hidup agar tidak menjadi sakit sehingga dapat menjalankan aktifitas sebagaimana mestinya. Di seluruh dunia terdapat lebih dari 2500 spesies nyamuk meskipun sebagian besar dari spesies-spesies nyamuk ini tidak berasosiasi dengan penyakit. Praktik pemberantasan jentik dapat dilakukan dengan $3 \mathrm{M}$ plus. Peran serta masyarakat dalam pemberantasan sarang nyamuk lebih diutamakan kepada ibu rumah tangga karena umumnya yang bertanggung jawab mengurus rumah tangga termasuk masalah kebersihan rumah. Penelitian ini bertujuan untuk mengetahui hubungan pendidikan dan pengetahuan dengan perilaku ibu rumah tangga dalam pemberantasan sarang nyamuk. Menggunakan metode analitik Cross Sectional, Teknik pengambilan sampel menggunakan Simple Random Sampling dan kriteria inklusi sehingga diperoleh responden sebanyak 50 orang. Analisis data dengan menggunakan Chi - Square dengan taraf signifikan yang digunakan adalah 95\% dengan nilai kemaknaan 5\%. Hasil penelitian Responden dengan pendidikan tinggi umumnya berperilaku baik yaitu sebesar $73,1 \%$ begitu juga dengan pendidikan rendah umumnya berperilaku kurang baik yaitu sebesar $70,8 \%$. Responden dengan pengetahuan baik umumnya berperilaku baik yaitu sebesar $75 \%$ begitu juga dengan pengetahuan kurang baik umumnya berperilaku kurang baik yaitu sebesar 77,3\%. Ada hubungan antara pendidikan dengan perilaku ibu rumah tangga dalam pemberantasan sarang nyamuk dan Ada hubungan antara pengetahuan dengan perilaku ibu rumah tangga dalam pemberantasan sarang nyamuk.
\end{abstract}

Kata Kunci : Ibu Rumah Tangga, Pendidikan, Pengetahuan, Perilaku 


\section{PENDAHULUAN}

Dewasa ini banyak penyakit menular yang telah mampu diatasi bahkan ada yang telah dapat dibasmi berkat kemajuan teknologi dalam mengatasi masalah lingkungan biologis yang eret hubungannya dengan penyakit menular. Akan tetapi masalah penyakit menular masih tetap dirasakan oleh sebagian besar penduduk negara berkembang. Salah satunya adalah masalah penyakit menular yang penularannya melalui vektor nyamuk (Noor, 2006).

Nyamuk merupakan vektor atau penular utama dari penyakit-penyakit arbovirus (malaria, demam berdarah, chikungunya, demam kuning, encephalitis, dan lain-lain), serta penyakit-penyakit nematoda (filariasis), riketsia, dan protozoa (malaria). Di seluruh dunia terdapat lebih dari 2500 spesies nyamuk meskipun sebagian besar dari spesies-spesies nyamuk ini tidak berasosiasi dengan penyakit. Jenisjenis nyamuk yang menjadi vektor utama, biasanya adalah Aedes spp., Culex spp., Anopheles spp., dan Mansonia spp (Noor, 2006).

Pendidikan dan perilaku (pengetahuan, sikap dan tindakan) tentang hidup sehat adalah hal yang penting terutama diterapkan dalam hidup agar tidak menjadi sakit sehingga dapat menjalankan aktifitas sebagaimana mestinya. Praktik pemberantasan jentik dapat dilakukan dengan 3M plus, yaitu : (Depkes RI, 2006) Cara ini dikenal dengan 3M, yaitu menguras (dan menyikat) bak mandi, WC, dan lain-lain, Menutup penampungan air rumah tangga (tempayan, drum, dan lainlain), serta mengubur, menyingkirkan atau memusnahkan barang-barang bekas (seperti kaleng, ban, dan lain-lain). Pengurasan Tempat Penampungan Air (TPA) perlu dilakukan secara teratur sekurangkurangnya seminggu sekali agar nyamuk tidak dapat berkembang biak.

Aktifitas masyarakat kawasan pesisir yang jarang menguras bak kamar mandi, membiarkan genangan air di sekitar pekarangan rumah, membuang sampahsampah bekas di sekitar perumahan yang berpotensi menjadikan tempat berkembangbiak nyamuk, hal ini menyebabkan risiko tingginya populasi nyamuk meningkat, untuk itu perlu adanya upaya pemberantasan sarang nyamuk guna memutuskan rantai penularan penyakit yang disebabkan oleh nyamuk. Peran serta masyarakat dalam pemberantasan sarang nyamuk lebih diutamakan kepada ibu rumah tangga karena umumnya yang bertanggung jawab mengurus rumah tangga termasuk masalah kebersihan rumah adalah ibu rumah tangga.

Stephen and Timothy (2008), menjelaskan empat cara dalam pembentukan perilaku yaitu penegasan positif, penegasan negatif, hukuman, dan peniadaan. Penegasan positif adalah menindaklanjuti respons dari masyarakat yang menyenangkan, sedang yang tidak menyenangkan merupakan penegasan negatif. Hukuman merupakan kondisi yang tidak menyenangkan karena berupaya untuk meniadakan perilaku, sedang menghapuskan penegasan yang mempertahankan perilaku merupakan peniadaan. Penegasan positif dan negatif akan memperkuat respons dan perilaku, sedang hukuman dan peniadaan akan memperkecil respons dan perilaku.

Oleh karena belum adanya gambaran secara terperinci mengenai aktivitas ibu rumah tangga pada kawasan pesisir terkait dengan pemberantasan sarang nyamuk, maka penelitian ini akan memberikan masukan mengenai hubungan pendidikan dan pengetahuan dengan perilaku ibu rumah tangga dalam pemberantasan sarang nyamuk.

\section{METODE}

Penelitian ini bersifat analitik Cross Sectional, menurut Notoatmodjo (2010) adalah suatu penelitian untuk mempelajari suatu dinamika korelasi antara faktor-faktor 
resiko dengan efek, dan dengan suatu pendekatan, observasi ataupun dengan pengumpulan data pada suatu saat tertentu (point time approach).

Lokasi penelitian ini adalah di Kawasan pesisir Waiheru Ambon. Pengumpulan data dilaksanakan pada bulan Pertengahan Juli sampai pertengahan Agustus 2019.

Populasi dalam penelitian ini adalah seluruh ibu rumah tangga yang tinggal di kawasan pesisir Waiheru Ambon. Sampel pada penelitian ini adalah sebagian ibu rumah tangga di kawasan pesisir Ambon. Pemilihan sampel didasarkan pada kriteria inklusi yaitu telah berdomisili di kawasan pesisir lebih dari satu tahun, berusia lebih dari 20 tahun, dan bersedia menjadi sampel penelitian. Berdasarkan kriteria inklusi, sampel yang diperoleh dalam penelitian ini berjumlah 50 responden. Dalam penelitian ini, teknik pengambilan sampel adalah simple random sampling. Analisis data dengan menggunakan Chi - Square dengan taraf signifikan yang digunakan adalah 95\% dengan nilai kemaknaan 5\%.

\section{HASIL}

\section{Analisis Univariat}

\section{Pendidikan}

Tabel 1. Distribusi Frekuensi Pendidikan Ibu Rumah Tangga Menurut Kelompok Umur di kawasan pesisir Waiheru Ambon Tahun 2019

\begin{tabular}{clc}
\hline Pendidikan & Frekuensi & persentase \\
\hline SD & 11 & $22 \%$ \\
SMP & 13 & $26 \%$ \\
SMA & 19 & $38 \%$ \\
PT & 7 & $14 \%$ \\
\hline Total & $\mathbf{5 0}$ & $\mathbf{1 0 0 \%}$
\end{tabular}

Berdasarkan tabel 1. didapatkan hasil, frekuensi tertinggi adalah berpendidikan SMA sebanyak 19 responden $(38 \%)$ dan frekuensi terendah adalah berpendidikan PT sebanyak 7 responden (14\%).

Untuk keperluan analisis bivariate, kategori pendidikan dibuat menjadi 2 yaitu
: Tinggi (PT dan SMA) dan Rendah (SMP dan SD)

Pengetahuan

Berdasarkan tabel 2. didapatkan hasil, frekuensi terbanyak adalah yang berpengetahuan kurang sebanyak 22 responden (44\%), dan frekuensi terendah adalah yang berpengetahuan Baik sebanyak 13 responden $(26 \%)$.

Untuk keperluan analisis bivariate, kategori pengetahuan dibuat menjadi 2 yaitu : Baik (Cukup dan Baik) dan Kurang Baik (Kurang Baik).

Tabel 2. Distribusi frekuensi Pengetahuan Ibu Rumah Tangga dalam Pemberantasan Sarang Nyamuk di Kawasan Pesisir Waiheru Ambon Tahun 2019

\begin{tabular}{ccc}
\hline Pengetahuan & Frekuensi & persentase \\
\hline Baik & 13 & $26 \%$ \\
cukup & 15 & $30 \%$ \\
Kurang & 22 & $44 \%$ \\
\hline Total & $\mathbf{5 0}$ & $\mathbf{1 0 0 \%}$ \\
\hline
\end{tabular}

Perilaku

Tabel 3. Distribusi Frekuensi Perilaku Ibu Rumah Tangga dalam Pemberantasan Sarang Nyamuk di Kawasan Pesisir Waiheru Ambon Tahun 2019

\begin{tabular}{ccc}
\hline Perilaku & Frekuensi & persentase \\
\hline Baik & 14 & $28 \%$ \\
cukup & 12 & $24 \%$ \\
Kurang & 24 & $48 \%$ \\
\hline Total & $\mathbf{5 0}$ & $\mathbf{1 0 0 \%}$ \\
\hline
\end{tabular}

Berdasarkan tabel 3. didapatkan hasil, frekuensi terbanyak adalah berperilaku Kurang sebanyak 24 responden (48\%), dan frekuensi paling sedikit adalah yang berperilaku Baik sebanyak 14 responden $(28 \%)$.

Untuk keperluan analisis bivariate, kategori perilaku dibuat menjadi 2 yaitu: Baik (Cukup dan Baik) dan Kurang baik (kurang baik) 
$\begin{array}{lllll}6 & 0 & 4 & 0 & 0\end{array}$

Analisis Bivariat

Hubungan pendidikan dengan perilaku

Tabel 4. Hubungan antara Pendidikan dengan Perilaku Ibu Rumah Tangga dalam Pemberantasan Sarang Nyamuk di Kawasan Pesisir Waiheru Ambon Tahun 2019

\begin{tabular}{|c|c|c|c|c|c|c|c|}
\hline \multirow{3}{*}{$\begin{array}{l}\text { Pendidi } \\
\text { kan }\end{array}$} & \multicolumn{4}{|c|}{ Perilaku } & \multirow{3}{*}{$\begin{array}{l}\text { Tot } \\
\text { al }\end{array}$} & \multirow{3}{*}{$\%$} & \multirow{3}{*}{$\begin{array}{c}P \\
\text { Valu } \\
\boldsymbol{e}\end{array}$} \\
\hline & \multicolumn{2}{|c|}{ Baik } & \multicolumn{2}{|c|}{$\begin{array}{l}\text { Kurang } \\
\text { baik }\end{array}$} & & & \\
\hline & f & $\%$ & f & $\%$ & & & \\
\hline \multirow[t]{2}{*}{ Tinggi } & 1 & 73 , & 7 & 26 , & 26 & 10 & \multirow{4}{*}{$\begin{array}{c}0,00 \\
2\end{array}$} \\
\hline & 9 & 1 & & 9 & & 0 & \\
\hline \multirow[t]{2}{*}{ Rendah } & 7 & 29 & 1 & 70 , & 24 & 10 & \\
\hline & & 2 & 7 & 8 & & 0 & \\
\hline \multirow[t]{2}{*}{ Total } & 2 & 52 , & 2 & 48 , & 50 & 10 & \\
\hline & 6 & 0 & 4 & 0 & & 0 & \\
\hline
\end{tabular}

Berdasarkan Tabel 4. diketahui bahwa responden dengan pendidikan tinggi, umumnya berperilaku baik yaitu sejumlah 19 responden (73,1 \%), sedangkan responden berpendidikan rendah, umumnya memiliki perilaku kurang baik yaitu 17 responden $(70,8 \%)$. Hasil Chi -Square menunjukkan $\mathrm{p}$ value $0,002<$ nilai $\alpha 0,05$ sehingga disimpulkan bahwa pendidikan berhubungan dengan perilaku responden.

Hubungan Pengetahuan dengan perilaku

Tabel 5. Hubungan antara Pengetahuan dengan Perilaku Ibu Rumah Tangga dalam Pemberantasan Sarang Nyamuk di Kawasan Pesisir Waiheru Ambon Tahun 2019

\begin{tabular}{cccccccc}
\hline \multirow{2}{*}{$\begin{array}{c}\text { Pengetah } \\
\text { uan }\end{array}$} & \multicolumn{9}{c}{ Perilaku } & & \multicolumn{1}{c}{$\begin{array}{c}\text { Kuran } \\
\text { g baik }\end{array}$} & $\begin{array}{l}\text { Tot } \\
\text { al }\end{array}$ & $\%$ & $\begin{array}{c}\boldsymbol{P} \\
\text { Value }\end{array}$ \\
\cline { 2 - 5 } & $\mathbf{f}$ & $\%$ & $\mathbf{f}$ & $\%$ & & & \\
\hline Baik & 2 & 75, & 7 & 25, & 10 & \\
& 1 & 0 & & 0 & 0 & 0,0 \\
\hline Kurang & 5 & 22, & 1 & 77, & 10 & 00 \\
Baik & & 0 & 7 & 3 & 0 & \\
\hline Total & 2 & 52, & 2 & 48, & 10 & \\
\hline
\end{tabular}

Berdasarkan Tabel 5. diketahui bahwa responden yang berpengetahuan baik, umumnya berperilaku baik yaitu sejumlah 21 responden $(75,0 \%)$, sedangkan responden berpengetahuan kurang baik umumnya memiliki perilaku kurang baik yaitu sejumlah 17 responden $(77,3 \%)$. Hasil chi- square menunjukkan $\mathrm{p}$ value $0,000<$ nilai $\alpha$ 0,05 sehingga disimpulkan bahwa pengetahuan berhubungan dengan perilaku responden.

\section{PEMBAHASAN}

\section{Hubungan pendidikan dengan perilaku}

Setelah dilakukan penelitian terhadap 50 responden ibu rumah tangga di kawasan pesisir Waiheru Ambon tahun 2019 berdasarkan pendidikan, bahwa pendidikan tinggi umumnya berperilaku baik yaitu sebesar $73,1 \%$ begitu juga dengan pendidikan rendah umumnya berperilaku kurang baik yaitu sebesar 70,8\% .

Dari data tersebut, bahwa pendidikan ibu rumah tangga berhubungan dengan perilaku yang ditunjukkan dalam pemberantasan sarang nyamuk. Hal ini sejalan dengan penelitian yang dilakukan oleh Suwarno tahun 2014 yang memperoleh hasil Tingkat pendidikan berpengaruh positif terhadap perilaku masyarakat dalam pengelolaan lahan pada masing-masing kelas kerawanan longsor lahan.

Pendidikan masyarakat ditentukan berdasarkan tahun sukses yaitu banyaknya tahun yang dihabiskan untuk sekolah bukan berdasarkan ijazah terakhir yang dimiliki. Masyarakat yang berpendidikan akan memiliki pengetahuan yang berpengaruh pada perilaku. Dimyanti dan Mudjiono (2009), Abraham (1991) Inkeles dan Smith (1976) dalam Suwarno (2014) mengemukakan pendidikan merupakan 
prediktor yang kuat dan konsisten terhadap sikap, nilai, dan perilaku seseorang untuk masa depannya.

Penelitian ini juga sejalan dengan penelitian yang dilakukan oleh Rahardjo, S. tahun 2011 yang memperoleh hasil ada hubungan antara pendidikan dengan perilaku KADARZI di Puskesmas I Kembaran.

Mulyasa dalam Fatih, F.D (2015) menyebutkan bahwa pendidikan pada hakekatnya adalah proses pematangan kualitas hidup. Sehingga idealnya pendidikan dapat membawa manusia menuju kualitas hidup yang lebih baik. Jadi, pendidikan adalah segala upaya yang dilakukan dengan sadar dan terencana guna meningkatkan mutu kehidupan.

\section{Hubungan Pengetahuan dengan perilaku}

Setelah dilakukan penelitian terhadap 50 responden ibu rumah tangga di kawasan pesisir Waiheru Ambon tahun 2019 berdasarkan pengetahuan bahwa pengetahuan baik umumnya berperilaku baik yaitu sebesar $75 \%$ begitu juga dengan pengetahuan kurang baik umumnya berperilaku kurang baik yaitu sebesar $77,3 \%$.

Dari data tersebut, pengetahuan ibu rumah tangga berhubungan dengan perilaku yang ditunjukkan dalam pemberantasan sarang nyamuk. Hal ini sejalan dengan penelitian yang dilakukan oleh Fauzian, R.A tahun 2016 yang memperoleh hasil bahwa didapatkan hubungan yang signifikan antara pengetahuan mengenai Glaukoma dengan perilaku memeriksakan diri ke pelayanan kesehatan mata.

Hal tersebut sesuai dengan teori pembentukan perilaku, bahwa munculnya sebuah perilaku dilatarbelakangi oleh stimulus. Stimulus tersebut menghasilkan respon yang muncul dari dalam diri individu sebagai inner drive atau dorongan dari dalam. Inner drive digunakan seseorang untuk memenuhi kebutuhan dalam menghadapi lingkungan yang dihadapinya. Pengetahuan merupakan salah satu stimulus dalam pembentukan perilaku tersebut (Budioro B dalam Fauzian, R.A, 2016)

Hasil penelitian ini juga sejalan dengan penelitian yang dilakukan oleh Febrianto, M.A.B tahun 2016 yang memperoleh hasil adanya hubungan antara pengetahuan dan sikap responden dengan perilaku pemilhan jajanan sehat. Notoatmodjo (2010) dalam penelitiannya mengungkapkan bahwa perilaku yang didasari oleh pengetahuan akan lebih langgeng daripada perilaku yang tidak didasari oleh pengetahuan.

\section{KESIMPULAN}

Dari hasil penelitian Perilaku ibu rumah tangga dalam pemberantasan sarang nyamuk di kawasan pesisir Waiheru Ambon 2019, dapat diambil kesimpulan bahwa :

Responden dengan pendidikan tinggi umumnya berperilaku baik yaitu sebesar $73,1 \%$ begitu juga dengan pendidikan rendah umumnya berperilaku kurang baik yaitu sebesar $70,8 \%$.

Responden dengan pengetahuan baik umumnya berperilaku baik yaitu sebesar $75 \%$ begitu juga dengan pengetahuan kurang baik umumnya berperilaku kurang baik yaitu sebesar 77,3\%.

Ada hubungan antara Pendidikan dengan perilaku responden dimana hasil statistik $p$ value $0,002<$ nilai $\alpha 0,05$.

Ada hubungan antara pengetahuan dengan perilaku responden dimana hasil statistik $\mathrm{p}$ value $0,000<$ nilai $\alpha 0,05$.

\section{DAFTAR PUSTAKA}

Departemen Kesehatan RI. (2004) Perkembangan Kasus Demam Berdarah di Indonesia. http://www.depkes.go.id. Diakses tanggal 30 Agustus 2019. 
Fatih, D.F. (2015) Hubungan Antara Tingkat Pendidikan dengan Sikap dan Perilaku Ibu Rumah Tangga Dalam Pemeliharaan Kebersihan Lingkungan Tempat Tinggal di Desa Klaling Kecamatan Jekulo Kabupaten Kudus. Skripsi. Semarang: Jurusan Geografi Fakultas Ilmu Sosial Universitas Negeri Semarang.

Fauzian, R.A., Rahmi, F.L., dan Nugroho, T. (2016) 'Hubungan Tingkat Pengetahuan Dengan Perilaku Memeriksakan Diri Ke Pelayanan Kesehatan: Penelitian Pada Pasien Glaukoma Di Rumah Sakit Dr. Kariadi', Jurnal Kedokteran Diponegoro, vol. 5, no. 4, pp. 16341641.

Febriyanto M.A.B. (2016) Hubungan Antara Pengetahuan dan Sikap Dengan Perilaku Konsumsi Jajanan Sehat di MI Sulaimaniyah, Mojo Agung, Jombang. Skripsi. Surabaya: Program Studi Kesehatan Masyarakat Universitas Airlangga Surabaya.

Noor, Nasry (2006) Pengantar
Epidemiologi Penyakit Menular, Jakarta: Rineka Cipta.

Notoatmodjo, S. (2010) Metodologi Penelitian Kesehatan, Jakarta: Rineka Cipta.

Rahardjo, S. dan Kusumawati, E. (2011) 'Relationship Between Education And Knowledge With Kadarzi Behavior In Rural Areas Represented By Kembaran I District', Jurnal Kesmasindo, Volume 4, Nomor 2, pp. 150-158.

Stephen, P.R., and Timothy, A.J. (2008) Perilaku Organisasi (Organizational Behavior), Jakarta: Salemba Empat.

Suwarno, J. Sartohadi, Sunarto, dan D. Sudharta (2014) 'Kajian Pengaruh Tingkat Pendidikan Terhadap Perilaku Masyarakat Dalam Pengelolaan Lahan Rawan Longsorlahan Di Kecamatan Pekuncen Kabupaten Banyumas', Jurnal Geoedukasi, Volume III Nomor 1, hlm. 15-22. 